\title{
Nephrogenic systemic fibrosis: concepts and perspectives *
}

\author{
Fibrose nefrogênica sistêmica: conceitos e perspectivas
}

\author{
Ana Carolina de Souza Machado Igreja ${ }^{1}$ \\ Shawn Edwin Cowper ${ }^{3}$
}

\author{
Kleyton de Carvalho Mesquita ${ }^{2}$ \\ Izelda Maria Carvalho Costa ${ }^{4}$
}

\begin{abstract}
Nephrogenic systemic fibrosis is a chronic, progressive condition that develops in some patients with renal impairment after exposure to gadolinium-based contrast agents used in magnetic resonance imaging. Thickening of the skin is typical, usually affecting the extremities. Visceral organs can also be affected. The diagnosis of the disease requires careful clinicopathological correlation. Treatment aims at restoring renal function, which is associated with delayed progression and, eventually, remission of skin changes. Reduction and prevention of nephrogenic systemic fibrosis cases are based on limiting the use of gadolinium-based contrast agents in patients with kidney disorders (especially in patients with advanced renal failure at stages 4 and 5), and restricting their use to situations in which they are essential to diagnosis/follow-up. Other than limiting exposure to gadolinium based contrast agents, no effective preventive methods have been reported. Due to increased awareness about the disease among radiologists and nephrologists, the incidence of nephrogenic systemic fibrosis is declining.

Keywords: Contrast media; Gadolinium; Magnetic resonance imaging; Nephrogenic fibrosing dermopathy; Renal insufficiency

Resumo: Fibrose nefrogênica sistêmica é condição crônica, progressiva, desenvolvida caracteristicamente em pacientes nefropatas após exposição a contrastes radiológicos que contenham gadolínio. O espessamento cutâneo é aspecto típico, envolvendo predominantemente as extremidades. Envolvimento visceral pode ocorrer. O diagnóstico da doença requer cuidadosa correlação clínico-patológica. O tratamento visa à restauração da função renal, que se associa ao retardo da progressão e, eventualmente, remissão das alterações cutâneas. A prevenção da ocorrência e redução da incidência baseiam-se na limitação do uso de contrastes à base de gadolínio em nefropatas (especialmente na insuficiência renal avançada em estágios 4 e 5), restringindo-os às condições nas quais seja imprescindível ao diagnóstico/acompanhamento. À exceção da restrição de exposição aos agentes de contraste a base de gadolínio, não há métodos preventivos efetivos relatados. Devido à ampla divulgação da doença entre radiologistas e nefrologistas, a incidência da fibrose nefrogênica sistêmica está em declínio.

Palavras-chave: Dermopatia fibrosante nefrogênica; Gadolínio; Imagem por ressonância magnética; Insuficiência renal; Meios de contraste
\end{abstract}

Received on 21.01.2012.

Approved by the Advisory Board and accepted for publication on 28.03.2012

* Work performed at the Universidade de Brasília, Hospital Universitário de Brasília, Dermatology Department - Brasília (DF), Brazil and the Yale University New Haven - Connecticut, USA.

Conflict of interest: None

Financial Support: None

Medical Resident in Dermatology, Hospital Universitário de Brasília (UnB), Brasília, Federal District, Brazil.

Masters student in Health Sciences at the Universidade de Brasília (UnB). Dermatologist at the State Health Department - Brasília (DF), Brazil.

Dermatologist and Pathologist, Associate Professor of Dermatology and Pathology, Yale University, New Haven, Connecticut, USA.

PhD in Dermatology awarded by the Universidade Federal de São Paulo (UNIFESP). Adjunct Professor of Dermatology, Universidade de Brasília (UnB) - Brasília (DF), Brazil.

CC2012 by Anais Brasileiros de Dermatologia 


\section{INTRODUCTION}

Nephrogenic systemic fibrosis (NSF) was first recognized in 1997 and described in 2000 by Cowper et $\mathrm{al}^{1}$ as a scleromyxedema-like illness in patients with chronic renal insufficiency (CRI) on renal replacement therapy, being characterized as progressive cutaneous fibrosis. At that time, only the skin was thought to be involved in the disease, which was called nephrogenic fibrosing dermopathy. Later, multisystem organ involvement (lung, liver, muscles- including the myocardium) was described, and the nomenclature was changed to NSF.

To date, all reports have been described in patients with acute or chronic renal insufficiency. ${ }^{1-8}$ Association with prior exposure to gadolinium-based contrast agents (GBCA) was first reported in 2006. Patients on renal replacement therapy are believed to be at greater risk of developing NSF when on peritoneal dialysis compared to hemodialysis. ${ }^{2,9}$

The typical clinical symptom is hardening of the skin, generally of the extremities but sometimes extending to the trunk. There is associated brawny hyperpigmentation, frequently accompanied by sensory symptoms. Joint contractures are common, and frequently lead to impaired mobility. Laboratory may be helpful to exclude the differential diagnosis of NSF. An anatomopathological analysis should always be performed to confirm diagnosis. There is no universally effective treatment, although patients early in their course frequently show improvement following a successful renal transplant. Prevention is mandatory in patients at risk.

\section{EPIDEMIOLOGY}

NSF is a rare condition, with fewer than 500 cases reported in the literature. ${ }^{2,10,11}$ It has no predilection for gender or ethnicity, and it most often affects middle-aged individuals, but there are reports of cases occurring from childhood to senescence..$^{2,4,10-13}$ Also, there is no predilection for etiology or duration of renal failure.$^{4,8}$ A cohort study developed in the United States of America in 2007 with patients on dialysis showed a $2.4 \%$ risk of developing the disease after exposure to gadolinium-based contrast media of different formulations. ${ }^{14}$ Patients on peritoneal dialysis appear to be at greater risk than those on hemodialysis. ${ }^{4,15}$

The disease was described after the introduction of GBCA in high concentrations to perform magnetic resonance angiography in 1997 and after its use in a significant number of patients with renal impairment. At that time, the use of GBCA represented the possibility of avoiding the use of iodinated contrast media in patients who already had significant renal function impairment. Moreover, the use of increasing cumulative doses of gadolinium-based compounds appears to have contributed to the increased incidence of NSF. ${ }^{12}$

\section{PATHOGENESIS \\ Gadolinium}

Gadolinium (Gd) is a rare lanthanide metal present in contrast media used to perform magnetic resonance imaging (MRI). ${ }^{412}$ The association between the use of GBCA and the development of NSF was first suggested in 2006 by Grobner ${ }^{16}$ in Austria and Marckman et al. in Denmark. ${ }^{17}$

The usual dose of Gd is $0.1 \mathrm{mmol} / \mathrm{kg}$, but it is higher for magnetic resonance angiography examinations, which pose a greater risk of developing NSF. Its toxic ionic form $\left(\mathrm{Gd}^{3+}\right)$ is administered in combination with larger organic molecules - chelates - forming stable complexes. ${ }^{4}$ These complexes are rapidly excreted in individuals with normal renal function, and their use is considered safe in these cases. If $\mathrm{Gd}^{3+}$ dissociates from its ligand, it binds with plasma phosphate and forms insoluble molecules. After abnormal vascular extravasation, precipitated phosphate salts may deposit in the interstitium and be phagocytized by macrophages, producing profibrotic cytokines. Other increased anions in renal insufficiency may also precipitate $\mathrm{Gd}^{3+2}$.

The mechanisms through which injury is caused in the skin and other organs are not well understood. ${ }^{12,16,17-19}$ The discovery of Gd deposits in the skin of affected patients ${ }^{12}$ led to the recommendation of cautious use of these contrast agents in patients with CRI by the Food and Drug Administration (FDA) and the European Medicines Agency (EMA).

In individuals with normal renal function, gadolinium based contrast agents have half-life of 2 hours. ${ }^{12}$ GBCA are eliminated by glomerular filtration, without contribution of tubular secretion and its renal clearance ranges from 1.1 to $1.6 \mathrm{ml} / \mathrm{kg} / \mathrm{min}$. Over $95 \%$ of the injected dose is eliminated within 24 hours and less than $3 \%$ in the feces. ${ }^{4}$ Since clearance is almost exclusively renal, GBCA elimination time is prolonged in patients with renal impairment. ${ }^{20}$ Clearance of the contrast agent in anuric patients is performed exclusively by dialysis. ${ }^{6,10}$ About $93 \%$ of Gd is removed after two consecutive sessions of hemodialysis, ${ }^{12}$ but this number is significantly lower when it comes to peritoneal dialysis, which clears about $75 \%$ of the lanthanide after 5 days. This difference is due to the relatively low molecular weight, low volume of distribution and low protein-binding characteristics of the complexes with $\mathrm{Gd} .^{21}$ The pharmacokinetic profile of Gd in healthy individuals and in individuals with renal impairment is showed in table $1 .{ }^{20}$

A study by Joffe et al. showed low peritoneal 
TABLE 1: Pharmacokinetic profile of Gd in healthy individuals and in individuals with moderate and severe renal failure

\begin{tabular}{lll}
\hline Group of patients & $\mathbf{T}_{\mathbf{1} / \mathbf{2}}$ (hours) & Renal clearance of Gd (ml/min) \\
\hline Healthy individuals with normal renal function & 2.0 & 118 \\
Moderate renal failure $(\mathrm{CrCl} 31-60 \mathrm{ml} / \mathrm{min})$ & 5.6 & 47 \\
Severe renal failure $(\mathrm{CrCl} 10-30 \mathrm{ml} / \mathrm{min})$ & 9.2 & 22 \\
\hline
\end{tabular}

$\mathrm{T}_{1 / 2}$ : half-life, CrCl: creatinine clearance

clearance of Gd: $65 \%$ of the injected gadodiamide was eliminated during a hemodialysis session, while $69 \%$ was eliminated after 22 consecutive days of ambulatory peritoneal dialysis. ${ }^{22}$ The authors reported that Gd has a half-life of $34.3 \mathrm{~h}$ in nondialyzed patients with severe renal failure, which is reduced to $2.6 \mathrm{~h}$ with hemodialysis. Peritoneal dialysis was not effective in the removal of Gd.

According to their structure, GBCA can be divided into macrocyclic and linear forms. In the first category, $\mathrm{Gd}^{3+}$ is bound by several bonds to the inside of a ring shaped chelate molecule, making its release dependent on the simultaneous breaking of multiple bonds. As this is thermodynamically unlikely, there is greater protection against dechelation of the Gd ion. As for charge, GBCA can be ionic and nonionic. ${ }^{4,11,23-26}$ GBCA include nine different proprietary formulations, which are listed in chart $1 .{ }^{4,12,24-26}$

Although several GBCA are used in European countries, only two have been approved by the EMA for use throughout the European Union: Gadoversetamide (OptiMARK ${ }^{\oplus}$ ) and Gadofosveset (Vasovist $^{\circledR} /$ Ablavar $^{\circledR}$ ). The latter was authorized in 2005 and unauthorized in 2011.26 The EMA classifies contrast agents into high risk (OptiMARK ${ }^{\circledast}$, Omniscan $^{\circledast}$, Magnevist $^{\circledR}$ ), medium risk (Vasovist $^{\circledR}$, Primovist ${ }^{\circledR}$,

CHART 1: Gd chelates used for Magnetic Resonance Imaging

\begin{tabular}{|c|c|c|c|c|c|}
\hline Agent & Trade name & $\begin{array}{l}\text { Molecular } \\
\text { Structure }\end{array}$ & Charge & Elimination & Approval \\
\hline Gadopentetate dimeglumine & $\begin{array}{l}\text { Magnevist } \\
\text { Magnevistan }\end{array}$ & Linear & Ionic & Renal & $\begin{array}{l}\text { FDA (1988) } \\
\text { ANVISA }\end{array}$ \\
\hline Gadoteridol & ProHance & Cyclic & Nonionic & Renal & $\begin{array}{l}\text { FDA (1992) } \\
\text { ANVISA }\end{array}$ \\
\hline Gadodiamide & Omniscan & Linear & Nonionic & Renal & $\begin{array}{l}\text { FDA (1993) } \\
\text { ANVISA }\end{array}$ \\
\hline Gadoversetamide & OptiMARK & Linear & Nonionic & Renal & $\begin{array}{l}\text { FDA (1999) } \\
\text { EMA (2007) } \\
\text { ANVISA }\end{array}$ \\
\hline Gadobenate dimeglumine & MultiHance & Linear & Ionic & $\begin{array}{l}97 \% \text { Renal } \\
3 \% \text { Bile }\end{array}$ & FDA (2004) \\
\hline Gadoxetate disodium & $\begin{array}{l}\text { Eovist } \\
\text { Primovist }\end{array}$ & Linear & Ionic & $\begin{array}{l}50 \% \text { Renal } \\
50 \% \text { Bile }\end{array}$ & FDA (2008) \\
\hline Gadofosveset & Ablavar & Linear & Ionic & $\begin{array}{l}91 \% \text { Renal } \\
9 \% \text { Bile }\end{array}$ & FDA (2008) \\
\hline Gadobutrol & Gadovist & Cyclic & Nonionic & Renal & ANVISA \\
\hline Gadoteric acid & Dotarem & Cyclic & Ionic & Renal & ANVISA \\
\hline
\end{tabular}

FDA: Food and Drug Administration, EMA: European Medicines Agency, ANVISA: National Health Surveillance Agency 
MultiHance $^{\circledR}$ ) and low risk (Dotarem ${ }^{\circledast}$, ProHance ${ }^{\circledR}$ e Gadovist ${ }^{\circledR}$.

It has been shown in murine models that deposition of Gd is greater in tissues when nonionic linear agents (gadodiamide) are used, followed by the use of ionic linear agents and, finally, macrocyclic agents. ${ }^{27}$ However, the risk of developing NSF with different GBCA has not yet been determined. Previous use of gadodiamide has been reported in most cases. ${ }^{12}$ The molecular structure and stability of the chelate seem to be involved in the development of $\mathrm{NSF}^{24}$

After 15 days of incubation in human serum, nonionic linear agents show in vitro release of $\mathrm{Gd} 10$ times higher when compared with ionic linear agents. Elevated serum phosphate accelerates the release of $\mathrm{Gd}^{3+}$ from nonionic linear agents and, to a lesser extent, from ionic linear agents. Macrocyclic agents are the most stable in vitro, in media with normal or high phosphate concentrations. ${ }^{28}$

A retrospective study covering a period of 8 years (1999 - 2007) with data from 94,917 patients exposed to Gd showed a mean dose of $54 \mathrm{ml}$ of contrast agent in patients who developed histologically proven NSF. Gadodiamide was the contrast agent used in $69.3 \%$ of all exposures. ${ }^{5}$ An association between higher cumulative dose of GBCA and development of NSF has not yet been proved, although some data do seem to suggest it.

New contrast agents show utilizing a hepatobiliary clearance route may be as effective as those using exclusively renal elimination. If a route is impaired, the other becomes responsible for eliminating a greater fraction of GBCA. Despite the scarcity of cases reported in relation to these newer contrast agents, one cannot discard their potential to trigger NSF, given their lower frequency of use, predominant use in patients with liver disease and the knowledge that radiologists had about NSF when these new agents were launched. According to the FDA, there is no contrast agent considered completely safe for use in patients with renal impairment.

NSF risk stratification based on the pharmacological properties of GBCA represents an attractive hypothesis, however, it has not yet been proven. Focusing on chemical aspects leads to neglect of other important considerations in the context of NSF.

\section{Chronic Renal Insufficiency (CRI)}

To date, all reported cases of NSF were developed by individuals with impaired renal function. ${ }^{2,5,710,12,25}$ Most cases occur in patients with CRI (stages 4 and 5), patients on renal replacement therapy (hemodialysis and peritoneal dialysis) and kidney transplant recipients. ${ }^{25,29}$ However, NSF can also develop after exposure to GBCA in cases of acute kidney injury. No predisposing relationship has been proven between time of renal dysfunction, its etiology and type of replacement therapy and the development of NSF. ${ }^{10,12}$

CRI is classified into five stages, according to the estimated glomerular filtration rate (eGFR) (Table 2). Although most cases have been reported in patients with eGFR $<15 \mathrm{ml} / \mathrm{min} / 1.73 \mathrm{~m}^{2}$, triggering eGFR has not been established for the disease. ${ }^{12}$

\section{ETIOPATHOGENIC MECHANISMS}

The sequence of physiopathological events in NSF is not yet clear. ${ }^{4,5}$ Theories postulate that NSF results from activation of circulating fibrocytes, a population of bone marrow-derived circulating mesenchymal stem cells, that are induced by Gd to differentiate in the dermis into cells that functionally and histologically resemble dermal fibroblasts. Dermal fibroblasts of skin affected by NSF produce greater amounts of sulfated glycosaminoglycans when compared with fibroblasts of normal skin. It is still unclear which type of fibroblasts contributes to the development of NSF. Cowper and Bucala believe that it is the circulating fibrocytes, since the cells seen in tissues show expression of CD34 and procollagen $1 .^{30}$

The abnormal local enviroment may disrupt the normal process of fibrocytes maturation. Even though circulating fibrocytes recruitment suggests that NSF is a systemic disease, recent findings point that GBCA may also act locally, leading to inflammation and fibrosis of the tissues. ${ }^{18}$

Direct toxic effects are suggested by the presence of Gd deposits in the skin of individuals who develop NSF. ${ }^{12,31,32}$ In its free form, Gd interacts with extracellular phosphates to produce insoluble gadolinium phosphate, which is subsequently phagocytosed by tissue macrophages. These macrophages are presumed to produce pro-fibrotic cytokines that promote the migration of additional machophages and fibrocytes. ${ }^{2,4,6}$ Fibrosis results from the binding of these pro-

TABLE 2: Stages of CRI

\begin{tabular}{ll}
\hline CRI & $\begin{array}{l}\text { Estimated Glomerular } \\
\text { Filtration Rate }\end{array}$ \\
\hline Stage $0 *$ & $\geq 90 \mathrm{ml} / \mathrm{min} / \mathbf{1 . 7 3 m} 2$ \\
Stage $1^{* *}$ & $\geq 90 \mathrm{ml} / \mathrm{min} / \mathbf{1 . 7 3 \mathrm { m } ^ { 2 }}$ \\
Stage 2 & $60-89 \mathrm{ml} / \mathrm{min} / \mathbf{1 . 7 3 \mathrm { m } ^ { 2 }}$ \\
Stage 3 & $30-59 \mathrm{ml} / \mathrm{min} / \mathbf{1 . 7 3 \mathrm { m } ^ { 2 }}$ \\
Stage 4 & $15-29 \mathrm{ml} / \mathrm{min} / \mathbf{1 . 7 3 \mathrm { m } ^ { 2 }}$ \\
Stage $5 * * *$ & $<15 \mathrm{ml} / \mathrm{min} / \mathbf{1 . 7 3 m} 2$ \\
\hline
\end{tabular}

* Risk groups for CRI in the absence of renal impairment.

** Renal impairment with normal or increased eGFR .

*** Or renal impairment requiring permanent dialysis. 
fibrotic cytokines with their receptors on fibrocytes, stimulating extracellular matrix proteins and collagen synthesis. The initial cutaneous infiltrate containing CD68/factor XIIIa-positive dendritic cells could represent a possible host response to noxious stimuli. ${ }^{4}$

An increase in serum iron (Fe) concentration can induce in vivo transmetallation of $\mathrm{Gd}$, a phenomenon whereby free $\mathrm{Gd}$ is released from the chelate and subsequent binds to endogenous ions. Treatment with exogenous Fe and a chronic microinflammation state in CRI may contribute to the release of free Gd. ${ }^{19,33}$ The combination of free Gd and the toxic effects of Fe can result in initial tissue damage, especially in situations of inflammation and oxidative stress in patients with CRI. The underlying inflammation may facilitate profibrotic cytokines and chemokines synthesis. ${ }^{25}$

Erythropoietin (EPO), due to its fibrogenic properties, ${ }^{4}$ has been theorized to play a triggering or facilitating role in the pathogenesis of NSF in patients with CRI ${ }^{2,10}$ Since advanced renal dysfunction leads to insufficient endogenous production of EPO, patients on renal replacement therapy often use recombinant human EPO to maintain their red blood cell count. It is postulated that the ability of EPO to stimulate marrow cell lines may also provoke the secondary stimulation of fibrocyte production. ${ }^{4,34,35}$ A case-matched study of patients with NSF by the Centers for Disease Control did not identify EPO use as a significant risk factor for the development of NSF, however. ${ }^{15}$

Increased expression and activation of transglutaminases in NSF were documented, but with no exact role in the pathogenesis of the disease. ${ }^{2}$ Some patients present chronic liver disease, including hepatitis B or $\mathrm{C}^{36-38}$ Associations between hepatorenal syndrome and post liver transplantation period with development of NSF have been reported, ${ }^{39}$ although there is no greater risk in this clinical scenario than that attributed to renal failure alone.

If compared to other conditions that affect chronically nephropathic patients, NSF is considered to be rare. According to this, other patient's features may be required to the development of the fibrosing condition further than the exposition to GBCA. Vascular injuries and proinflammatory state are important risk factors to NSF onset. ${ }^{25}$ Until now no responsible etiopathogenic factors nor their specific roles have been defined.

Procoagulant states, recent surgery (especially vascular), deep vein thrombosis,${ }^{6,9,40,41}$ newly transplanted-kidney failure and sudden-onset kidney disease with significant swelling of the extremities may be associated with NSF. The injured vessels allow the dissociated Gd prompt penetration in the interstitial space and tissues. ${ }^{25}$ Surgery and thrombotic events fre- quently occur two weeks before the onset of cutaneous manifestations. ${ }^{10}$ Metabolic acidosis has also been associated with NSF, ${ }^{2}$ but has been repeatedly refuted as an independent risk factor. Both endothelial damage and hypercoagulability facilitate the migration of blood fibrocytes. ${ }^{10}$ Chart 2 summarizes the risk factors for developing NSF after use of GBCA.

\section{CLINICAL MANIFESTATIONS}

Cutaneous changes develop days to weeks after exposure to GBCA. They are characterized by thickening and hardening of the skin associated with brawny hyperpigmentation, typically presenting in a symmetric fashion. ${ }^{1,42}$ These changes initially affect the distal portion of the lower limbs, ${ }^{2}$ progressing proximally, sometimes reaching the trunk. Involvement of the lower limbs typically begins with the talocalcaneal joints, ascending to the central region of the thighs. As for involvement of the upper limbs, the changes initially occur on the wrists, also with ascendant progression to the arms. ${ }^{12}$ The face is typically not affected. There have been reports of edema and blisters on hands and feet. ${ }^{2} \mathrm{~A}$ rapidly progressive course is seen in $5 \%$ of the cases. ${ }^{10}$

The lesions may be pruritic, painful or present a local burning sensation. The initial manifestation may be a pruritic erythematous rash after exposure to the contrast agent. In many cases, there is edema of the affected areas before the appearance of the characteristic woody textures. ${ }^{4}$ Erythematous to hyperpigmented thickened plaques with an amoeboid aspect appear (Figure 1). Hypopigmented, erythematous or normochromic macules and papules may coalesce, forming plaques. The plaques may have a cobblestone appearance. The skin gradually becomes fibrotic and adherent to the underlying fascia, in a diffuse or linear fashion, with a woody consistency to palpation (Figure 2) ${ }^{12}$ It acquires a shiny aspect with perifollicular depressions, with a peau d'orange texture. Soft tissue calcifications are eventually revealed by radiographs. ${ }^{10}$

There might be joint motion restriction secondary to skin involvement. Joint contractures and motion restrictions may develop within days or weeks, leading to progressive limitation of daily activities and reduced patient's quality of life. ${ }^{12}$ The involvement of

Chart 2: Hypothesized risk factors for NSF after use of GBCA

\begin{tabular}{|ll|}
\hline CRI stages 4 to 5 & Vascular surgical procedures \\
Thrombotic events & Endothelial damage \\
Transplanted kidney failure & Hypercoagulability \\
Sudden-onset kidney disease &
\end{tabular}




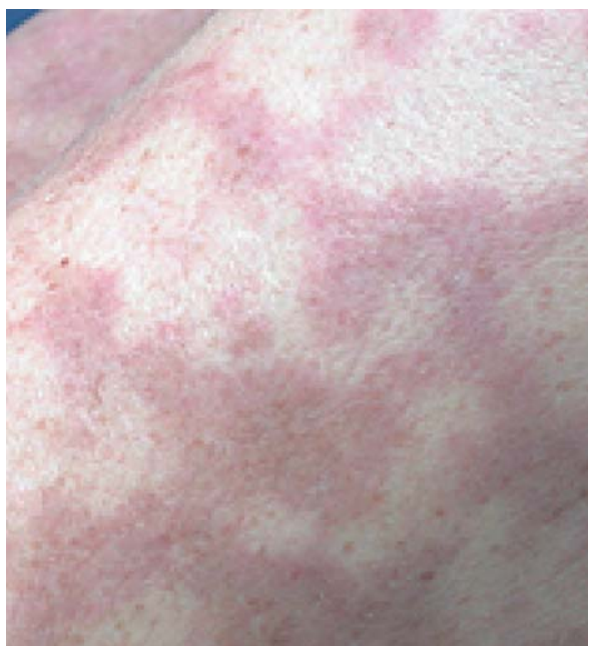

FIGURE 1:

Erythematousviolaceous thickened plaques with an amoeboid or reticular pattern

Reprinted from: Girardi M, et al. 2011. ${ }^{\top}$ Copyright 2010. Used with permission from Elsevier/American Academy of Dermatology, Inc.

tendons and periarticular tissues (without inflammation) also contributes to restriction of mobility.

Extracutaneous manifestations may occur, and no predictive factors have been identified so far. Telangiectasia and scleral plaques have been reported, but without visual acuity changes. ${ }^{2,42}$ Visceral and skeletal muscles may be affected. Gd deposition in the cardiac tissue can be as high as in the affected skin, ${ }^{43}$ which can lead to myocardial fibrosis. ${ }^{4}$ Fibrosis of serous membranes, including the meninges, may also occur. ${ }^{9,40,41}$ Systemic involvement may, therefore, lead to heart disease, pulmonary hypertension and muscle weakness. Fluctuating hypertension has been described prior to the development of cutaneous changes. ${ }^{2,10}$ As the disease progresses, hypotension and thromboembolic events may occur. Sensory-motor neuropathy occurs as a manifestation of peripheral nerve involvement.

Visceral involvement may be seen in patients with extensive skin disease. ${ }^{4}$ The prognosis varies depending on the severity of the systemic involvement, extent of skin lesions and time of onset.

\section{DIAGNOSIS}

To date, there are no laboratory and pathognomonic histopathological findings or findings consistently associated with the disease that allow its diagnosis in isolation. The diagnosis must be established by a correlation between clinical, laboratory and histopathological findings. The presence of fibrotic skin changes in a patient with renal impairment should prompt further investigation.

The diagnosis is confirmed by anatomopathological examination and the findings vary according to the stage of evolution of the disease. As a rule, the epi-

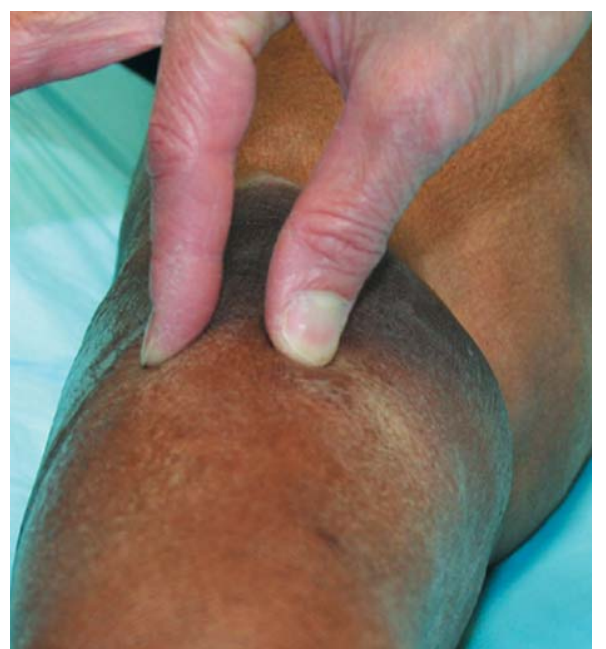

Figure 2: With the progression of the disease, the skin gradually becomes fibrotic and adherent to the underlying fascia, leading to with a woody consistency to palpation, with a shiny aspect. Peau d'orange texture may occur due perifollicular depressions

Reprinted from: Girardi M, et al. 2011. ' Copyright 2010. Used with permission from Elsevier/American Academy of Dermatology, Inc.

dermis is unaltered. The dermis shows increased deposition of collagen and mucin. Initially, deposits of mucin are prominent, separated by thin collagen bundles. With the advance of the disease, these collagen bundles thicken and are separated by clefts (Figure 3). There is no significant inflammation. In advanced stages, thick collagen bundles are separated by less prominent clefts, fibroblasts and elastic fibers. Clefts are present in all stages of the disease. The fibrotic process may extend to the subcutaneous tissue, widening the interlobular septa and yielding a microlobular architecture (Figure 4). ${ }^{2}$ Therefore, samples for biopsy should be of adequate depth and volume.

Fibrocytes - bone marrow-derived mesenchymal spindle cells - positive for $\mathrm{CD} 34$, procollagen 1 and vimentin, are found distributed between the collagen bundles, generally parallel to their predominant direction ${ }^{2,6}$ Recent lesions (within the first 20 weeks) show a great number of these cells in the reticular dermis in an interconnected manner. ${ }^{42}$ As the disease progresses, the expression of procollagen 1 by fibrocytes increases, correlating with the extracellular deposition of collagen. ${ }^{6}$ Old lesions (over 20 weeks) show smaller mucin deposits, fewer fibroblasts and less prominent clefts. ${ }^{42}$ However, increasing numbers of fibroblasts and macrophages have been described with the progression of skin fibrosis. ${ }^{6}$ The precise role of fibrocytes in the etiopathogenesis of the disease is unclear. It is not known whether they trigger the fibrotic process (due to their ability to migrate to and enter damaged tissues) or simply maintain the development of fibrotic lesions.

Factor XIIIa-positive dendritic cells associated with CD68-positive histiocytes, mono-and multinucleated, are often found in affected tissues. An increa- 


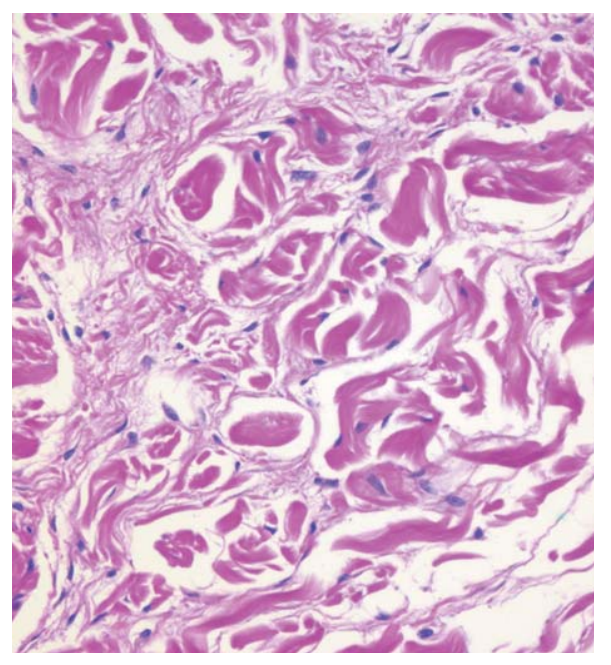

Figure 3: Typical thick collagen bundles surrounded by clefts. Thin collagen bundles may also be observed

Reprinted from: Girardi M, et al. 2011. ' Copyright 2010. Used with permission from Elsevier/American Academy of Dermatology, Inc.

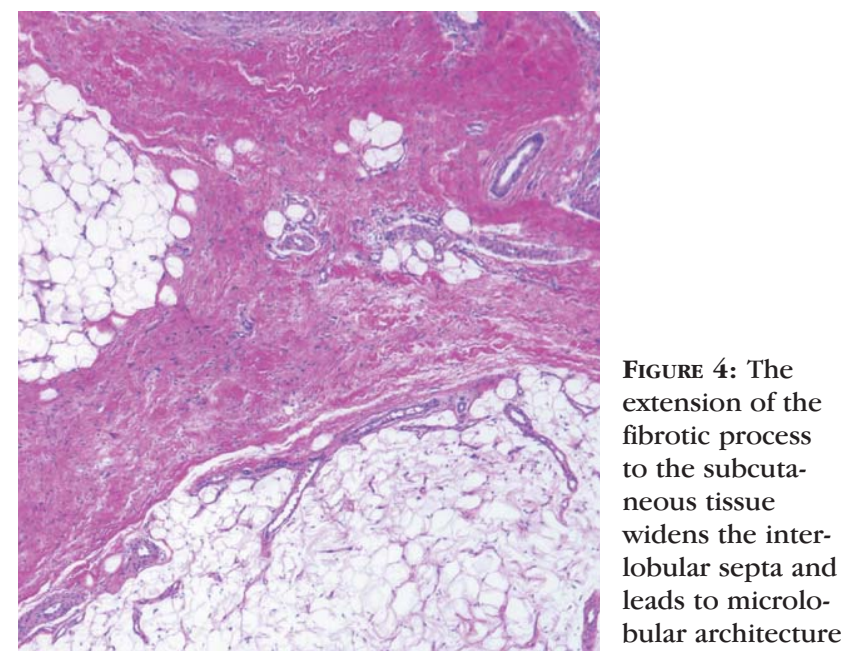

Reprinted from: Girardi M, et al. 2011. ${ }^{7}$ Copyright 2010. Used with permission from Elsevier/American Academy of Dermatology, Inc. sed number of dendritic cells, with co-expression of CD68 and factor XIIIa, has been shown in recent lesions of $\mathrm{NSF}^{2,12}$

Deposition of mucin, collagen and elastic fibers can be seen in specific staining - Alcian blue or colloidal iron, Verhoeff-van Gieson and Masson's trichrome, respectively. There are reports of calcification in and around collagen bundles and elastic fibers, as well as around the basement membrane of vessel walls and histiocytes. ${ }^{2}$

Similar histopathological changes are observed in the muscles underlying the affected areas. This does not occur in areas of healthy skin. Muscular involvement is associated with the extent of systemic involvement.

The presence of Gd deposits can be seen via spectrometry, but their intensity does not correlate with the extent of clinical involvement. The degree of fibrosis noted histopathologically does correlate with the local concentration of deposited Gd. ${ }^{44,45}$ Therefore, the significance Gd deposition is unclear to diagnosis and prognosis, and is not a necessary finding to render a diagnosis of $\mathrm{NSF}^{2,6}$ The concentration of Gd in the tissues of patients with NSF is 35 to 150 times higher than in normal individuals exposed to Gd. ${ }^{25,44}$ Perivascular deposits of Gd and Fe have also been demonstrated. ${ }^{46}$

Girardi et al. proposed major and minor clinical and histopathological criteria for the diagnosis of $\mathrm{NSF}^{7}$ In their model, the demonstration and quantification of $\mathrm{Gd}$ deposits are not required for diagnosis. This definition of NSF was developed at Yale University as part of the International NSF Registry, and is based on nearly 400 cases in that collection. The study authors comprised a multidisciplinary clini- cal team with extensive experience with NSF. Further studies are needed to confirm clinical applicability and accuracy.

Positive serology for hepatitis B and C, eosinophilia, presence of antinuclear antibodies, anticardiolipin antibodies and/or antiphospholipid antibodies, as well as hypercoagulable state and alteration of inflammatory function tests are frequent laboratory findings. Increase in serum calcium and phosphate concentrations may also occur. ${ }^{12}$ However, among laboratory tests, changes resulting from loss of renal function are invariably found.

Due to the absence of pathognomonic findings, diagnosis is based on the presence of typical clinical manifestations in patients with renal impairment with compatible histopathological symptoms. The non-specificity of imaging findings for both the diagnosis and follow-up of patients with NSF restricts its use.

\section{DIFFERENTIAL DIAGNOSIS}

The differential diagnosis of NSF includes other disorders involving the presence of skin fibrosis and is done through clinical and histopathological findings.

Systemic sclerosis affects the trunk and limbs, similarly to NSF, but the face and neck are often affected. It is an autoimmune disease that involves the skin and other organs and is most commonly seen in women aged between 30 and 50 years. The American College of Rheumatology requires the presence of one major criterion (symmetric sclerosis proximal to the metacarpophalangeal or metatarsophalangeal joints) or two minor criteria (sclerodactyly, digital pitting scars or loss of substance from the finger pad; bibasilar pulmonary fibrosis). Telangiectasias and Raynaud's phenomenon are not seen with NSF. In the 
context of systemic sclerosis, such findings associated with calcinosis, sclerodactyly, and esophageal dysmotility constitute the CREST syndrome. Between 40 and $70 \%$ of the patients have anti-Scl-70 antibodies. The presence of antinuclear antibodies, antineutrophil cytoplasmic antibodies and antitopoisomerase antibodies also facilitates the diagnosis of systemic sclerosis. Thickened collagen bundles, vascular fibrosis, calcification and mild lymphoplasmacytic inflammatory infiltrate are observed by microscopy. The presence of autoantibodies and histopathological features allow the differential diagnosis. Patients with NSF do not have anticentromere and anti-Scl-70 antibodies, there is no facial involvement and associations with systemic symptoms are distinct. ${ }^{42}$

Scleromyxedema is a rare condition usually associated with monoclonal IgG- $\lambda$ paraproteinemia, which progresses to multiple myeloma in approximately $10 \%$ of the cases. ${ }^{2,42}$ It shows a distinct distribution pattern, with involvement of the face and neck. Patients with scleromyxedema show skin thickening and hardening due to increased production of mucin, collagen, fibroblast proliferation and dermal deposition of glycosaminoglycans. ${ }^{1}$ Unlike NSF, an inflammatory infiltrate with a variable number of plasma cells is observed. ${ }^{42}$ Skin changes are distributed in the upper hemibody, initially in the face. Systemic involvement occurs in all subtypes.

Lipodermatosclerosis shows skin changes restricted to the lower limbs and is due to vascular stasis. Joint contracture does not occur in this condition.

Graft versus host disease can be similar to NSF, presenting with dyschromic fibrotic plaques, but with typical involvement of the trunk. There is a history of allogeneic transplant before the onset of symptoms.

The presence of numerous CD34-positive fibroblasts in some cases of NSF requires differential diagnosis with dermatofibrosarcoma protuberans (DFSP). DFSP often presents with an extensive indurated plaque due to involvement of the subcutaneous tissue. It may occur above the neck facilitating differentiation from NSF, and histopathology is essential for diagnostic confirmation.

Eosinophilic fasciitis presents with sudden onset of pain, swelling and erythema of the extremities with rapid progression. It evolves to cutaneous sclerosis with contractures and restricted mobility within months. It affects the forearms, arms, legs, thighs and trunk; there is peripheral eosinophilia, increased erythrocyte sedimentation rate and hypergammaglobulinemia in most cases. ${ }^{42}$ Hyalinization and thickening of the collagen bundles of the deep fascia and subcutaneous tissue, with clusters of eosinophils, are also observed.

Metastatic calcifications, calciphylaxis, eosinophi- lia-myalgia syndrome and porphyria cutanea tarda also constitute the range of differential diagnoses of NSF.

Exclusive involvement of patients with renal impairment, history of exposure to GBCA and typical distribution of skin lesions of NSF favor the differential diagnosis.

\section{TREATMENT}

There is no specific treatment established. The main objective in the management of patients with NSF is recovery of the renal function, which relates to delay of disease progression, regardless of the treatment adopted..$^{10}$ Spontaneous resolution of NSF in renal transplant recipients has been reported. ${ }^{2}$ Nevertheless, lesions may remain unchanged after renal transplantation, even if the transplanted organ shows normal function.

The therapeutical approaches described are anedoctal and include corticosteroids (topical and systemic), topical vitamin $\mathrm{D}$ analogues, other immunomodulators (methotrexate, thalidomide), vascular compression stockings, extracorporeal photopheresis, plasmapheresis and chelates, among others.

The use of oral prednisone $1 \mathrm{mg} / \mathrm{kg} /$ day shows conflicting results. ${ }^{4,10}$ Its prolonged use may result in significant adverse effects such as osteoporosis, poor glycemic control in diabetics and increased risk of gastrointestinal ulceration. Pulses of methylprednisolone followed by weekly methotrexate in a pediatric patient yielded a good clinical outcome, but neutropenia proved to be a potentially fatal complication. ${ }^{13}$ Development of NSF in patients taking low doses of prednisone has been described. ${ }^{8}$

The use of occlusive calcipotriol appears to be of little value ${ }^{3}$ however, the combination of calcipotriol with high-potency topical corticosteroids and vascular compression stockings proved to be effective in some cases. ${ }^{10,13}$

Patients with recent onset of the disease may show improvement of skin lesions after treatment with thalidomide (50 to $100 \mathrm{mg}$ daily), which apparently does not occur in patients with long-standing disease. ${ }^{2,3}$ However, there are reports of the development of NSF in patients who were already using thalidomide to treat other comorbidities. ${ }^{10}$

Reduction of the fibrotic consistency of plaques after extracorporeal photopheresis in patients diagnosed with NSF for less than one year has been described, but patients who had been diagnosed with NSF for a period longer than 12 months showed no response to this therapy. None of the patients evaluated showed improvement of renal function, which suggests that the therapeutic benefit was exclusively due to photopheresis. ${ }^{47}$ Because this treatment is safe and relatively free of adverse effects, it should be conside- 
red in the initial management of $\mathrm{NSF}^{12}$ but its use is restricted by its high cost and limited availability.

Phototherapy with UVA and psoralens (PUVA), associated or not with acitretin and prednisone, has also proven to be effective for a limited number of patients. ${ }^{10}$ Due to the potential reduction in collagen synthesis secondary to the suppression of proinflammatory cytokines, photodynamic therapy, photopheresis and UVA phototherapy are promising alternatives. ${ }^{4}$

Plasmapheresis was also effective for 3 patients who had undergone liver and kidney transplantation; however, it is not known whether this satisfactory response was due to improved renal function., ${ }^{3,10}$

High-dose intravenous immunoglobulin showed good results, as well as the use of intravenous sodium thiosulfate in a restricted number of patients, possibly due to their chelating and antioxidant properties. ${ }^{2-4,48}$

Pentoxifylline (1200mg daily) slowed the progression of and stabilized the disease due to its antifibrotic activity resulting from antagonism to tumor necrosis factor alpha and from an increase in the flexibility of red blood cells, which improves peripheral circulation and reduces the incidence of thrombotic events. ${ }^{16}$

Imatinib mesylate (Gleevec ${ }^{\circledast}$ - Novartis) inhibits the synthesis of fibronectin and type I collagen by dermal fibroblasts in vitro. It may also reduce the synthesis and accumulation of extracellular matrix as previously shown for bleomycin-induced dermal fibrosis. Treatment of NSF patients with imatinib has been showing promising results. ${ }^{49}$ Persistent clinical and histologic improvements were observed with the use of $400 \mathrm{mg}$ daily. The clinical benefits were maintained regardless of $\mathrm{Gd}$ tissue deposition. ${ }^{50}$ The standard duration of the treatment is yet to be determined since skin abnormalities may recur after its interruption. Further studies are still necessary to better understand imatinib's role in the treatment of NSF and other fibrotic conditions. 2,3,50,51 Cyclophosphamide did not show favorable results. ${ }^{4}$

Physiotherapy appears to be useful in preventing and delaying the progression of joint restrictions, as well as in restoring joint mobility. It should be prescribed whenever possible. Better results were obtained with swimming., ${ }^{2,10,12}$

Even though recent reports show clinical improvement of NSF after kidney transplantation, ${ }^{52}$ there are only few cases described and not all the cases have shown benefits from this approach. To date, kidney transplantation's role in the management of NSF still needs to be elucidated, lacking enough evidence for further conclusions and recommendations. It should be noted that NSF itself does not contraindicate renal transplantation.
Reports of improvement with all treatment options are anecdotal; thus, there are no specific recommendations for the therapeutic management of these patients so far.

\section{PROGNOSIS}

Improvement of renal function is associated with that of skin lesions, which can resolve spontaneously following the restoration of normal renal function. However, the disease is progressive in most cases. So far there are no reports of spontaneous regression of NSF not associated with improvement of renal function. Despite the fact that improvement of fibrotic symptoms is associated with improvement of renal function, there are reports of development of NSF in renal transplant patients after normalization of renal function.

Cardiovascular diseases are the leading cause of death in chronic terminal patients with renal impairment with or without NSF. Increased mortality in patients with terminal renal disease with NSF is reported compared with those who do not have the disease. NSF does not directly cause death, but restrictions caused by the fibrotic state may predispose to a lethal outcome. $^{2,10}$

Although not immediately life threatening, NSF is a limiting condition with a major impact on quality of life. It may result in joint contractures, reduced mobility, and frequent falls and fractures. A multidisciplinary, integral approach is essential, as well as orientation about the chronic and often progressive character of the disease, for which there is no current effective treatment.

\section{PREVENTION}

The occurrence of NSF is closely related to the exposure of patients with GFR $<30 \mathrm{ml} / \mathrm{min} / 1.73 \mathrm{~m}^{2}$ to GBCA. Due to the exclusive occurrence of the disease in patients with renal impairment, non-use or cautious use of GBCA in these individuals seems to be the only preventive measure. An agent with preventive properties for use in patients at risk has not yet been described. Patients with stages 4 and 5 CRI and severe acute renal failure should not be exposed to GBCA. They should also be avoided in the milder stages of renal failure due to the progressive and debilitating nature of the disease. Alternative imaging studies should be prioritized.

The FDA and the American College of Radiology recommend considering hemodialysis immediately after or less than 2 hours after exposure to GBCA for patients with stage 5 CRI and severe acute renal insufficiency (ARI), which is also acceptable for patients already on peritoneal dialysis. In dialysis patients, it is recommended to perform the test prior to dialysis, as 
well as suspend iron replacement a week before MRI. ${ }^{53}$ Due to the high morbidity associated with the placement of a large-caliber catheter for dialysis, hemodialysis is not indicated for patients with stage 4 CRI. For these patients, the recommendation for testing must be accurate and the free consent form must be signed. ${ }^{12}$ The performance of hemodialysis after MRI removes approximately $75 \%$ of the contrast agent present in a dialysis session and 95\% of this agent after three sessions. However, there are no studies that prove the theoretical benefit of early dialysis. ${ }^{54}$ Repeated examinations should be avoided and any contrast dose administered should be as small as possible. The use of a macrocyclic GBCA is preferred by some authors in patients at increased risk in whom contrast imaging cannot be avoided.

American and European recommendations for the safe use of GBCA include: avoid use in patients with severe renal impairment (give preference to computed tomography with iodinated contrast agents), in the perioperative period of liver transplantation, in neonates and breastfeeding infants younger than 4 months (due to their immature kidneys); use the lowest recommended dose, avoid multiple exposures to $\mathrm{Gd}$; minimum interval of 1 week between tests; track nephropathy prior to administration of contrast; avoid use of linear chelating agents; consider dialysis after contrast administration in patients on renal replacement therapy. It is suggested that patients on dialysis undergo 3 consecutive dialysis sessions, the first within 2 hours after contrast expo- sure; increase the number of dialysis bag exchanges for patients on peritoneal dialysis and evaluate the need for hemodialysis in these patients. There is no evidence confirming that dialysis should be introduced to prevent or treat NSF in non-dialytic patients. ${ }^{26}$

\section{CONCLUSION}

NSF is a rare disease exclusive of patients with renal impairment (acute or chronic) exposed to GBCA, with a significant reduction of eGFR. Its physiopathogenic mechanisms remain unclear but appear closely related to the persistence of GBCA material in the peripheral tissues of those at risk. No standard treatment has been established. Similarly, the prognosis is still uncertain and responses to therapeutic approaches are controversial. Preventing the establishment of NSF appears to be the only certainty in this enigmatic context.

The low incidence of NSF and the complexity of affected patients are insurmountable obstacles to the development of human controlled studies. Experimental animal models have been proposed, but there are still clinical-pathological discrepancies compared to human cases. ${ }^{18}$

Cautious use of GBCA in patients with renal disease has dramatically reduced the number of new cases of NSF since the FDA's initial warnings, in June of 2006. Therefore, it is expected that with the restrictions on the use of these contrasts, especially in patients with stages 4 and 5 CRI and severe ARI, NSF will become a historical disease.

\section{REFERENCES}

1. Cowper SE, Robin HS, Steinberg SM, Su LD, Gupta S, LeBoit PE. Scleromyxoedema-like cutaneous diseases in renal-dialysis patients. Lancet 2000;356:1000-1.

2. Basak P, Jesmajian S. Nephrogenic Systemic Fibrosis: Current Concepts. Indian J Dermatol. 2011;56:59-64

3. Cordova KB, Oberg TJ, Malik M, Robinson-Bostom L. Dermatologic conditions seen in end-stage renal disease. Semin Dial. 2009;22:45-55

4. Mundim JS, Lorena SC, Abensur H, Elias RM, Moysés RMA, Castro MCM, Romão Júnior JE. Nephrogenic systemic fibrosis: a severe complication of use to gadolinium in patients with kidney failure. Rev Assoc Med Bras. 2009;55:220-5.

5. Lee CU, Wood CM, Hesley GK, Leung N, Bridges MD, Lund JT, et al. Large sample of nephrogenic systemic fibrosis cases from a single institution. Arch Dermatol. 2009:145:1095-102

6. Newton BB, Jimenez SA. Mechanism of NSF: new evidence challenging the prevailing theory. J Magn Reson Imaging. 2009:30:1277-1283.

7. Girardi M, Kay J, Elston DM, LeBoit PE, Abu-Alfa A, Cowper SE. Nephrogenic Systemic Fibrosis: Clinicopathological definition and workup recommendations. J Am Acad Dermatol. 2011;65:1095-1106.e7.
8. Introcaso CE, Hivnor C, Cowper S, Werth VP. Nephrogenic fibrosing dermopathy/nephrogenic systemic fibrosis: a case series of nine patients and review of literature. Int J Dermatol. 2007;46:447-452.

9. Knopp EA, Cowper SE. Nephrogenic systemic fibrosis: early recognition and treatment. Semin Dial. 2008;21:123-8.

10. icnsfr.org.[homepage]. Nephrogenic Fibrosing Dermopathy [ICNSFR Website] 2001-2009. [cited 2011 May 28]. Available from: http://www.icnsfr.org.

11. Braverman IM, Cowper SE. Nephrogenic systemic fibrosis. F1000 Med Rep. 2010;2:84 -8.

12. Kribben A, Witzke O, Hillen U, Barkhausen J, Daul AE, Erbel R. Nephrogenic systemic fibrosis: pathogenesis, diagnosis, and therapy. J Am Coll Cardiol. 2009;53:1621-8

13. DiCarlo JB, Gupta EA, Solomon AR. A pediatric case of nephrogenic fibrosing dermopathy: Improvement after combination therapy. J Am Acad Dermatol. 2006:54:914-6.

14. Deo A, Fogel M, Cowper SE. Nephrogenic systemic fibrosis: a population study examining the relationship of disease development to gadolinium exposure. Clin J Am Soc Nephrol. 2007;2: 264-7. 
15. Centers for Disease Control and Prevention (CDC). Nephrogenic fibrosing dermopathy associated with exposure to gadolinium-containing contrast agents - St. Louis, Missouri, 2002-2006. MMWR Morb Mortal Wkly Rep. 2007;56:137-141.

16. Grobner T. Gadolinium - a specific trigger for the development of nephrogenic fibrosing dermopathy and nephrogenic systemic fibrosis? Nephrol Dial Transplant. 2006;21:1104-8.

17. Marckmann P, Skov L, Rossen K, Heaf JG, Thomsen HS. Case-control study of gadodiamide-related nephrogenic systemic fibrosis. Nephrol Dial Transplant. 2007;22:3174- 8.

18. Haemel AK, Sadowski EA, Shafer MM, Djamali A. Update on nephrogenic systemic fibrosis: are we making progress? Int J Dermatol. 2011;50:659-66.

19. Swaminathan S, Shah SV. New insights into nephrogenic systemic fibrosis. J Am Soc Nephrol. 2007;18:2636-43.

20. Swan SK, Lambrecht LJ, Townsend R, Davies BE, McCloud S, Parker JR, et al. Safety and pharmacokinetic profile of gadobenate dimeglumine in subjects with renal impairment. Invest Radiol. 1999; 34:443-55

21. Perazella MA, Rodby RA. Gadolinium use in patients with kidney disease: A cause for concern. Semin Dial. 2007;20:179-85.

22. Joffe P, Thomsen HS, Meusel M. Pharmacokinetics of gadodiamide injection in patients with severe renal insufficiency and patients undergoing hemodialysis or continuous ambulatory peritoneal dialysis. Acad Radiol. 1998;5:491-502.

23. Runge VM. Safety of magnetic resonance contrast media. Top Magn Reson Imaging. 2001;12:309-14.

24. Bruder O, Schneider S, Nothnagel D, Pilz G, Lombardi M, Sinha A, et al. Acute Adverse Reactions to Gadolinium-Based Contrast Agents in CMR. JACC Cardiovasc Imaging. 2011;4:1171 - 6 .

25. Perazella MA. Advanced kidney disease, gadolinium and nephrogenic systemic fibrosis: the perfect storm. Curr Opin Nephrol Hypertens. 2009;18:519 -25.

26. ema.europa.eu [homepage]. London: Questions and answers on the review of gadolinium-containing contrast agents. 2010. [cited 2011 Dec 11]. Available from: http://www.ema.europa.eu/docs/en_GB/document_library/Referrals_document/ga dolinium_31/WC500015635.pdf.

27. Sieber MA, Lengsfeld P, Frenzel T, Golfier S, Schmitt-Wilich H, Siegmund F, et al. Preclinical investigation to compare different gadolinium-based contrast agents regarding their propensity to release gadolinium in vivo and to trigger nephrogenic systemic fibrosis-like lesions. Eur Radiol. 2008;18:2164-73.

28. Frenzel T, Lengsfeld P, Schirmer H, Hütter J, Weinmann HJ. Stability of gadoliniumbased magnetic resonance imaging contrast agents in human serum at 37 degrees C. Invest Radiol. 2008;43:817-28.

29. Goddard DS, Magee CC, Lazar AJF, Miller DM. Nephrogenic fibrosing dermopathy with recurrence after allograft failure. J Am Acad Dermatol. 2007;56:S109-111.

30. Cowper SE, Bucala R. Nephrogenic fibrosing dermopathy: suspect identified, motive unclear. Am J Dermatopathol. 2003;25:358.

31. Boyd AS, Zic JA, Abraham JL. Gadolinium deposition in nephrogenic fibrosing dermopathy. J Am Acad Dermatol. 2007;56:27-30.

32. High WA, Ayers RA, Chandler J, Zito G, Cowper SE. Gadolinium is detectable within the tissue of patients with nephrogenic systemic fibrosis. J Am Acad Dermatol. 2007;56:21- 6 .

33. Idee JM, Port M, Raynal I, Schaefer M, Greneur SL, Corot C. Clinical and biological consequences of transmetallation induced by contrast agents for magnetic resonance imaging: a review. Fundam Clin Pharmacol. 2006;20:563-76.

34. Ballen K. Targeting the stem cell niche: squeezing blood from bones. Bone Marrow Transplant. 2007;39:655 - 60.

35. Heeschen C, Aicher A, Lehmann R, Fichtlscherer S, Vasa M, Urbich C, et al. Erythropoietin is a potent physiologic stimulus for endothelial progenitor cell mobilization. Blood. 2003; 102:1340-6.

36. Fazekas Z, Davies J, Phelps R, Lebwohl M. A case of nephrogenic fibrosing dermopathy in a liver transplant recipient. J Am Acad Dermatol. 2007;56:AB58.

37. Cowper SE, Boyer PJ. Nephrogenic systemic fibrosis: an update. Curr Rheumatol Rep. 2006;8:151-7.

38. Sadowski EA, Bennett LK, Chan MR, Wentland AL, Garret AL, Garret RW, et al. Nephrogenic systemic fibrosis: risk factors and incidence estimation. Radiology. 2007;243:148 - 57 .
39. Broome DR, Girguis MS, Baron PW, Cottrell AC, Kjellin I, Kirk GA. Gadodiamideassociated nephrogenic systemic fibrosis: why radiologists should be concerned. AJR Am J Roentgenol. 2007;188:586-92.

40. Cowper SE. Nephrogenic systemic fibrosis: an overview. J Am Coll Radiol. 2008;5:23- 8

41. Cowper SE, Rabach M, Girardi M. Clinical and histological findings in nephrogenic systemic fibrosis. Eur J Radiol. 2008;66:191-9.

42. Streams BN, Liu V, Liégeois N, Moschella SM. Clinical and pathologic features of nephrogenic fibrosing dermopathy: a report of two cases. J Am Acad Dermatol. 2003;48:42-7

43. Swaminathan S, High WA, Ranville J, Horn TD, Hiatt K, Thomas M, et al. Cardiac and vascular metal deposition with high mortality in nephrogenic systemic fibrosis. Kidney Int. 2008; 73:1413- 8.

44. High WA, Eng M, Ayers RA, Cowper SE. Gadolinium is quantifiable within the tissue of patients with nephrogenic systemic fibrosis. J Am Acad Dermatol. 2007;56:710-2

45. High WA, Ranville JF, Brown M, Punshon T, Lanzirotti A, Jackson BP. Gadolinium deposition in nephrogenic systemic fibrosis: an examination of tissue using synchrotron x-ray fluorescence spectroscopy. J Am Acad Dermatol. 2010;62:38 - 44.

46. Schroeder JA, Weingart C, Coras B, Hausser I, Reinhold S, Mack M, et al. Ultrastructural evidence of dermal gadolinium deposits in a patient with nephrogenic systemic fibrosis and endstage renal disease. Clin J Am Soc Nephrol. 2008;3:968 - 75 .

47. Richmond H, Zwerner J, Kim Y, Fiorentino D. Nephrogenic systemic fibrosis: Relationship to gadolinium and response to photopheresis. Arch Dermatol. 2007;143:1025- 30.

48. Yerram P, Saab G, Karuparthi PR, Hayden MR, Khanna R. Nephrogenic systemic fibrosis: a mysterious disease in patients with renal failure - role of gadoliniumbased contrast media in causation and the beneficial effect of intravenous sodium thiosulfate. Clin J Am Soc Nephrol. 2007;2:258-63.

49. Elmholdt TR, Pedersen M, Jørgensen B, Ramsing M, Olesen AB. Positive effect of low-dose imatinib mesylate in a patient with nephrogenic systemic fibrosis. Acta Derm Venereol. 2011;91:478-9.

50. Kay J, High WA. Imatinib mesylate treatment of nephrogenic systemic fibrosis Arthritis Rheum. 2008;58:2543-8.

51. Chandran S, Petersen J, Jacobs C, Florentino D, Doeden K, Lafayette RA. Imatinib in the treatment of nephrogenic systemic fibrosis. Am J Kidney Dis. 2009;53:129 $-32$.

52. Cuffy MC, Singh M, Formica R, Simmons E, Abu Alfa AK, Carlson K, et al. Renal transplantation for nephrogenic systemic fibrosis: a case report and review of the literature. Nephrol Dial Transplant. 2011;26:1099-101.

53. Mayr M, Burkhalter F, Bongartz G. Nephrogenic Systemic Fibrosis: Clinical Spectrum of Disease. J Magn Reson Imaging. 2009;30:1289 -97.

54. Saxena SK, Sharma M, Patel M, Oreopoulos D. Nephrogenic systemic fibrosis: an emerging entity. Int Urol Nephrol. 2008;40:715-24.

\author{
MAILING ADDRESS: \\ Ana Carolina de Souza Machado Igreja \\ Hospital Universitário de Brasília \\ Serviço de Dermatologia \\ SGAN 605, Avenida L2 Norte, Brasília - DF \\ CEP: 70840 - 901 \\ e-mail: anacaroligreja@gmail.com
}

How to cite this article: Igreja ACSM, Mesquita KC, Cowper SE, Costa IMC. Nephrogenic systemic fibrosis: concepts and perspectives. An Bras Dermatol. 2012;87(4):597-607. 